\title{
Die Voortrekkerideaal - Natal of Transvaal?
}

JP Oberholzer

Universiteit van Pretoria

\begin{abstract}
The Voortrekker ideal - Natal or Transvaal?

On the basis of several documents from prominent Voortrekker leaders their ideal is summarised as follows: They were seeking for a space in which they could enjoy responsible freedom together with a means of living, and could sustain their freedom by sclf government, good relations with other peoples and defence of person, land and property. From the inception of the idea of emigration the ultimate distination was seen differently by leaders, but eventually it was the Transvaal which provided the first real fulfillment of the ideal in the form of independence acknowledge by Great Britain.
\end{abstract}

Die woord Voortrekkerideaal of verwante vorme word nogal gebruik in literatuur oor die Groot Trek. Wat die ideaal of ideale was, word egter selde duidelik uitgespel.

As ons die manifes van Piet Retief as basis neem, sou ons so 'n ideaal moes formuleer aan die hand van die volgende frases (Duvenage 1987: $98 \mathrm{vv}$ ):

- geluk of vrede vir ons kinders;

- die regverdige beginsels van vryheid gestand doen;

- misdaad onderdruk;

- 'n behoorlike verhouding tussen meester en kneg handhaaf;

- 'n rustige lewe lei;

- persoon en eiendom tot die uiterste verdedig;

- 'n wetstelsel vir eie dissipline;

- straf van verraaiers;

- vrede en vriendskap met swart stamme;

- onsself sonder inmenging regeer; 
- diens en gehoorsaamheid aan God.

Uit die Uys-verklaring van die Caledon af op 14 Augustus 1837 kom die volgende:

- We place our dependence on the All-wise Ruler of heaven and earth, and are resolved to adhere to the sure foundation of our reformed christian religion, entertaining the hope when we have reached the place of our destination, we shall live a better and safer life.

- When we shall have attained our object, and have arrived at the place of our destination, we then trust to see the whole of our countrymen assembled together; then, by the public voice, to proceed to the election and appointment of our chief rulers, and the framing of proper laws, and in general to consider what is useful both for country and people.

- We purpose to establish our settlement on the same principles of liberty as those adapted by the USA carrying into effect, as far as practible, our burgher laws (Chase I: $103 \mathrm{v}$ ).

Andries Hendrik Potgieter skryf op 3 Desember 1838 aan goewerneur Napier in dieselfde trant, sy dit minder wel ter tale:

- ... het ons dit goedgevind om tot behoud van ons gesinne die Kolonie te verlaat

- ons beskou ons as vry burgers wat kan gaan waar ons verkies sonder om iemand te benadeel

- ons oogmerk was na 'n land waar geen (ander) nasies was nie

- ons wil niemand van die nasies wat hier is, benadeel nie (VA R20/38).

In die skrywe van die Natalse Volksraad aan goewerneur Napier, 14 Januarie 1841, word die ideaal miskien die volledigste saamgevat: 
Om op die beste en vriendskaplike terme met die Britse regering te staan, en indien moontlik in vrede met die volkere wat ons omring, te bly verkeer, en wens ons alleen om onsself op ons wettige grondgebied te beskerm en te regeer sonder om ooit aan of u regering of die nasies wat ons omring enige skade toe te bring as hulle wederkerig begerig mag wees om met ons in vrede te lewe (VA R72/41).

As ons uit hierdie vier belangrike Voortrekkerdokumente 'n samevatting kan probeer maak van die Voortrekkerideaal, kan dit dalk soos volg lyk: Hulle was op soek na 'n ruimte waarbinne hulle naas lewensmoontlikheid ook verantwoordelike vryheid sou kon geniet en daardie vryheid sou kon handhaaf deur selfregering, verstandhouding met ander volke en verdediging van persoon, bodem en eiendom.

In hierdie sin sou ons met sekere voorbehoud kon onderskryf wat SP Engelbrecht in 1938 oor hierdie saak gesê het. 'Dit word ook algemeen erken dat die Trek maar een enkele oorsaak gehad het, en dit was die ontwakende drang van 'n wordende nasie om homself te wees' (Engelbrecht 1938: 127). Dit was 'n ideaal met 'n ekonomiese en politieke inhoud.

Van ekonomiese kant sou dit voorsien kon word dat daar 'n verskil sou kon ontstaan tussen die skaapboere en die beesboere oor die geskikste ruimte vir bewoning. Die uitgestrekte grasvlaktes van die sentrale hoëveld was vir die skaapboer die aangewese woonplek as daar tegelyk brandhout beskikbaar was. Die omvang van dié aspek blyk daaruit dat iemand soos Louis Trichardt en sy seun Carolus voor die Trek 'n veestapel gehad het van sowat 1300 beeste, 8000 skape en bokke en 33 perde (VM II 1920). Dit verklaar waarom die trekgeselskappe oor die algemeen hoofsaaklik familietrekke was tot oor Grootrivier, en dat daarvandaan eers geselskappe by mekaar aangesluit het, deels omdat daar noord van die Grootrivier groter onbewoonde ruimtes was, deels ter wille van beskerming.

Hermanus Potgieter (AH se vader) se besittings word in 1811 opgegee as 178 beeste, 5800 kleinvee en 22 perde (Duvenage 1981: 143). AH Potgieter self het in 1825 (toe hy 33 jaar was) 130 beeste, 1050 skape en 25 perde besit (Duvenage 1981: 145). Enige beskouing oor die trekbeweging moet in ag neem dat die geweldige veetroppe groot eise gestel het ten opsigte van weiding, water, bewaking, koers en spoed. Wat die trekrigting betref, het die swaarwig van bees- of skaapbesit dus waarskynlik meegespreek, soos enkele geskiedskrywers reeds uitgewys het (Wichman 1941: 6,7; Muller 1943: 31).

Wichman het uit die bewegings van die Tregard- en Van Rensburg geselskappe afgelei dat hulle trekrigting reeds lank tevore 'n uitgemaakte saak was en dat hulle die Hoëveld bo Natal as woonplek verkies het (Wichman 1941: 6, 7). Daar is inder- 
daad heelwat getuienis wat daarop dui dat die meeste Voortrekkers reeds voor hulle vertrek uit die Kolonie al 'n gedagte oor die trekrigting gehad het.

Ongelukkig is die verslae van die drie verkenningskommissies wat in die loop van 1834 Damaraland, die Oorvaalse en Natal verken het, nie bewaar nie, en beskik ons oor weinig gegewens oor die verloop van die verkenningstogte. Bekend is wel dat die verslag oor Damaraland, dit is die suidelike deel van SWA, negatief was (Duvenage 1986: 36; Bird 1965: 231). Die aard van die verslag van die Oorvaalse verkenningstog onder leiding van Scholtz, wat tot aan Soutpansberg gevoer het en onder andere kontak met die familie van Coenraad Buys gemaak het, is nie bekend nie, maar ons kan aflei dat dit gunstig was en dat die trekgeselskappe van Tregard, Van Rensburg en AH Potgieter daardeur beïnvloed is. Hierdie drie geselskappe het allerlei onderlinge familieverbintenisse gehad en dit kom voor of daar van die begin af 'n onderlinge verstandhouding tussen hulle was, 'n verstandhouding wat deur die Van Rensburgmoord en deur die Matabele-aanvalle aan die Vaalrivier belemmer is. Dit kom voor of ook die Potgieter-geselskap op pad was verder noord (LR Bester by Spies 1959: 239) en dat Tregard se verblyf in Soutpansberg deels 'n tyd van wag op die 'agterste mense' was, deels 'n tyd van onsekerheid oor die verdere koers, gesien die lot van die Van Rensburg-geselskap. Die eerste bedoeling was om kontak te maak met Delagoabaai (Dicke 1941: 93), naamlik om handelsmoontlikhede daar te stel. Daarnaas is die soeke na 'n geskikte woonruimte nie uit die oog verloor nie. Carolus Tregard het vertel dat sy vader hom in Julie 1838 uit Delagoabaai op 'n verkenningstog gestuur het om 'n landstreek te vind wat 'vir 'n groot nedersetting geskik is' (VM II: 12).

Potgieter en sy mense se ideale is effektief gestuit deur die Matabele. Vanaf sy terugkeer uit Soutpansberg ná sy verkenningstog na die noorde tot einde 1837 sou die Matabele en hulle optrede hom en sy geselskap voluit in beslag neem. Die aanvalle op die jagkamp van Erasmus en op die Liebenbergs aan Vaalrivier, die slag aan die Vaalrivier en die slag van Vegkop het 'n noodsaak geskep, nie net met die oog op toekomstige veiligheid aan weerskante van die Vaalrivier nie, maar met die oog op oorlewing. Die paar families wat by hierdie botsing met die Matabele betrokke was, is geruïneer deur die wegvoering van al hulle vee. Volgens 'n mededeling van Potgieter aan Erasmus Smit het Potgieter self in hierdie botsings $\mathbf{4 0 0}$ beeste en 5000 skape verloor (VM II: 63).

Intussen het die trekstroom breër begin vloei, en is sake gekompliseer deur verskillende oortuigings oor die trekrigting. Reeds in Desember 1834 word daar berig dat die Uys-kommissie wat na Natal se kant toe verkenning gedoen het, van mening was dat hulle beeste goed sou aard op die Natalse weiveld en dat sommige lede van die verkenningsgroep van voorneme was om hulle daar te vestig (Muller 
1943: 19). As lede van die Uys-kommissie word genoem: Pieter Lafras Uys, Pieter Lafras Moolman, sy neef, Evert F Potgieter, Jacobus Moolman, Gert Rudolph, Stephanus Maritz, e a. Ons tref van hierdie persone later aan by verskillende trekgeselskappe. Gert Rudolph was 'n prominente lid van die Maritz-trek en ook 'n neef van Gert Maritz. Evert Potgieter en Stephanus Maritz het in Januarie 1837 by Blesberg aangekom. Dit verbaas dus nie dat in die Maritz-, Retief-, Uys- en Landman-trekke daar eenstemmigheid oor Natal as bestemming was nie.

Erasmus Smit rapporteer op 2 Mei 1837: 'Daar was 'n klein verskil, of liewer 'n misverstand, by sommige oor die pad waarlangs ons van hier (dit is van Houtnek af) verder sou voortreis na die Vetrivier.' Teen dié tyd was die eerste strafekspedisie teen Silkaats afgeloop met beperkte resultate ten opsigte van die kompensasie vir die veeverliese van die Potgietergeselskap en met 'n verdere resultaat van spanning tussen Potgieter en Maritz. Verder was teen dié tyd die vestiging van die regeringstelsel met Retief as goewerneur, Gert Maritz as magistraat en nog 5 persone as lede van die Raad van Policie afgehandel. Hiervandaan kry ons nou egter te doen met 'n moeilik ontrafelbare stukkie geskiedenis.

AH Potgieter het op 8 Mei met sy laer vertrek in hun weg, die zij voor zich verkosen te reizen (VM II: 96). Ernstige spanning tussen die onderskeie leiers oor 'n verskeidenheid van sake het in hierdie tyd na vore gekom en daartoe bygedra dat goewerneur Retief ernstige probleme ondervind het om eendragtige optrede te kry. Die trekrigting was hiervan slegs 'n onderdeel. Op $18 \mathrm{Mei}$ was daar weer 'n groot byeenkoms waar oor die reis verder beraadslaag is, maar drie dae later praat Smit gewoon van die 'reisende gemeente van die Gereformeerde Kerk na Port Natal', en op 22 Mei skryf hy: 'In die voormiddag het ons 'n ent verder voortgery na Port Natal.' In sy gemoed was daar dus net een bestemming. Wat hy verder skryf oor volksvergaderings op 29 Mei en 23 Junie in verband met die verdere voortreise van die laers, het blykbaar meer te doen gehad met die tyd en wyse van die trek na Natal as met die verskil oor trekrigting. Op 6 Junie is immers besluit oor die naam van die nuwe land wat hulle sou stig: 'Die Vrye Provinsie van Nieu-Holland in SuidOos-Afrika.' Retief stuur op 4 Julie vyf persone om 'n pad na Port Natal te verken, en op 14 Julie slaag Retief daarin om vrede tussen hom, Maritz, Rudolph en Oosthuizen te bereik. Maar op 17 Julie rapporteer Smit: 'Die vrede van 14 deser was van korte duur. Vandag hoor ons weer van onvrede oor die weg wat ons moet reis; die een wil so, die ander weer 'n ander weg ingeslaan he.' Wanneer ons dan verneem dat die goewerneur wel op $18 \mathrm{Julie}$ ingewillig het 'om die weg weswaarts te reis wat $G$ Maritz en sy laerkring vandag gereis het na die Vaalrivier', wil dit voorkom of die konflik tussen Retief en Maritz, wat altwee Natal as bestemming gesien het, nie oor trekrigting gegaan het nie maar oor prioriteit. 
Maritz het hom by Potgieter aan die Suikerbosrand gaan voeg met die oog op die tweede veldtog teen Silkaats en hy is later deur Piet Uys gevolg. Hierdie veldtog is aanvanklik vir Juniemaand beplan, maar moes noodgedwonge uitgestel word weens onder andere gerugte oor bedreigings van die kant van die Griekwa en Koranna (Chase 1968: 88, 90; Preller 1920: 115). Met die beplanning van die veldtog was dit duidelik dat dit 'n onderneming sou wees van die verenigde Trekkergemeenskap onder leiding van goewerneur Retief (Chase 1968: 90, $111 \mathrm{v}$ ). Mettertyd het dit egter geblyk dat Retief voorkeur gegee het aan 'n spoedige oortog oor die Drakensberge. Reeds op 4 Julie stuur hy die verkennergroep van vyf man om passe oor die Drakensberg te soek, en volgens sy skrywe aan die Kaapse goewerneur op 9 September van Sandrivier af, was die verkenners na vyf en twintig dae terug met die verslag dat die Drakensberg op vyf verskillende plekke sonder gevaar oorgesteek kan word. Hy skryf onder andere: 'Het ons eerder geweet dat ons 'n oorgang oor die Drakensberg sou vind, was ons lankal aan die einde van ons reis. Volgens alle berigte is ons te verstaan gegee dat ons om die punt van die berg sou moes reis, wat ons heelwat noord sou gevoer het'.

Die roete wat nou gevind is, sou die roete na Natal met 'n volle twee maande verkort. Die plan was om reg oos te trek, maar omdat daar veldbrande was na die Drakensberg se kant toe en die ooie aan die lam was, is besluit dat die laer sou bly waar dit is en dat Retief self met vyftig man Port Natal en die Zoeloekoning Dingaan sou besoek.

Retief was van voorneme om reeds die 16de September te vertrek (Chase 1968; 111), maar uiteindelik kom hy eers op 6 Oktober weg, en dan nie met vyftig nie, maar met miskien sewentien man. Wat hom vertraag het, was onder andere die groot volksvergadering van 13 September, waar geskille tussen Piet Uys en die Potgieters aan die een kant en goewerneur Retief aan die ander kant bespreek is. Dit is by hierdie geleentheid dat Piet Uys op ' $n$ vraag oor die voortsetting van die trek sou gesê het: 'Een ieder gaat zijn weg: deze voor; anderen op zijde; genen zullen achteraan komen.' Daaruit moet ons aflei dat daar ooreengekom is om te verskil, waarskynlik nie alleen oor die bestemming nie, maar ook oor tyd en wyse.

Van al die belangriker trekleiers was dit trouens net Potgieter wat skynbaar van die begin af die verre noorde as bestemming gesien het, naamlik 'n ruimte agter Delagoabaai. Al die ander het al voor die vertrek uit die Kaap of die oop veld tussen die Oranje en Vaal in die oog gehad of Natal. So het veldkornet Gideon Joubert van Nieu-Hantam dit al in Februarie 1836 in 'n verslag gestel: '... het scheijnt soo als ik hoor seij eenige over de hoogeveld trekt na Port Natals seijde, eenige naa Vaalrivier, eenige sal svervende bleijven omtrent Modderrivier en bove langs Caledon' (Duvenage 1987: 115). Leiers van kleiner geselskappe het vrye 
keuse uitgeoefen afgesien van vroeëre assosiasies. Christiaan Liebenberg en Charl Cilliers wat lank by die Potgieter-trek was, het gekies vir Natal; JGS Bronkhorst en Gert Kruger het by Potgieter gebly; Pieter Daniel Jacobs het in die Vrystaatse gebied agtergebly. Dit kom voor of 'n belangrike deel van die geskil tussen Piet Uys en Piet Retief gelê het in die vraag wie die eintlike aanspraak op Natal het. Dit blyk al uit die Uys-verklaring van 14 Augustus aan die Caledon toe die familietrek nog op pad was (Chase 1968: $103 \mathrm{v}$ ), en dan veral uit die volksvergadering aan die Suikerbosrand voor die tweede strafekspedisie teen Silkaats. Volgens Izak Breytenbach het Uys daar sy rapport oor Natalland deur Jan Bantjes laat voorlees, waarop die besluit geneem is om na Natal toe te trek (VM III: 90, 91). Of Potgieter hom hier laat oorreed het om ook Natal as bestemming te kies, en of hy hom net tydelik by die Nataltrekkers gevoeg het, is onseker. Sy seuns Andries Hendrik en Willem het verklaar dat Retief hulle vader oorreed het om saam te trek, en LR Bester sê dat Potgieter hom te swak bevind het om sy voorneme te volg en toe vir Uys en Maritz oor die Drakensberg gevolg het (VM III: 6, 24; Spies 1959: 235 v). Feit is dat hy, blykbaar met 'n betreklik klein trekgeselskap, wel af Natal toe is ná die tweede veldtog teen Silkaats, wat teen 8 Desember afgeloop was. John Montgomery se vertelling bevestig dat Potgieter hom deur Retief laat oorhaal het en dat hy ook nie na Montgomery se raad wou luister om nie Natal toe te gaan nie (Giffard 1981: 128). Van Gass en Hatting praat albei van volksvergaderings ná die tweede veldtog teen Silkaats, en Van Gass en de Klerk praat van verkenningstogte wat in dié tyd onderneem is na Natal en Delagoabaai. Van dié een na Natal toe weet ons, maar oor die een na Delagoabaai het daar nie besonderhede oorgebly nie.

Die verslag van die Natalsending onder leiding van Piet Retief is behandel op 'n volksvergadering onderkant Drakensberg op 12 Desember. Toe was die deelnemers aan die tweede veldtog teen Silkaats egter nog nie in Natal nie. Piet Uys het op 15 Desember en Gert Maritz en Gert Rudolph die 16de daar aangekom. Geskille tussen Uys en Retief is bygelê op 'n vergadering op Maandag 18 Desember, en op 19 Desember is ' $n$ besluit geneem oor die ekspedisie na Sikonjela toe. Daarmee begin die Natalse tussenspel. AH Potgieter sou na die Italenislag Natal verlaat om nie weer terug te keer nie voordat hy namens die Adjunkraad van PotchefstroomWinburg sitting in die Natalse Volksraad geneem het op 2 Februarie 1841 (VM 101).

Ongelukkig is daar min bekend van wat 'Agter die berg' gebeur het in die jare 1838-1841. Potgieter het die grondruiling met Mokwana aangegaan, ses maande aan die Sandrivier gestaan en einde 1838 na Mooirivier versit, waar hy met behulp van 'n krygsraad 'n losse bewind gevoer het oor die Winburg-Mooirivier gebied. Groot dele van die Vrystaat en Suid-Transvaal was teen dié tyd bewoon. Die Voor- 
trekkerrepubliek met hoofsetel Pietermaritzburg sou vir talle persone wes van die Drakensberg 'n vae en selfs onbekende werklikheid bly, want hulle het die Voortrekkerideaal verwesenlik gevind in die Vrystaat en Transvaal. Die ruimte met die lewensmoontlikheid was daar, en hulle vryheid is suksesvol gehandhaaf deur selfregering, verstandhouding met ander volke en suksesvolle verdediging van persoon, eiendom en bodem. Die moeisame en pynlike geboorte van Natalia, sy waggelende kleutertyd en sy vroeë sterfte sou 'n herhaling bring van die migrasiebeweging - vir 'n tweede keer weg van 'n swak koloniale regering wat sy onderdane weerloos gelaat het teenoor die swart mag wat oor die grense gestroom het. Hierdie keer was dit die swaarverworwe vaste eiendom in Natal wat agtergelaat moes word, 'n stuk geskiedenis wat futiel gelyk het teen die agtergrond van die lyding en stryd wat dit gevul het. Dit is daarom miskien 'n bietjie ironies dat dit juis die Natalse episode is wat die hoofrol speel in die heroïese statuur van die Groot Trek. Weliswaar het die gebied wes van die Drakensberg 'n beduidende kwota deelnemers aan die Wenkommando gelewer. ' $n$ Mens dink aan Kmd Pieter Daniel Jacobs met sy kommando, aan die dertien man wat deur AWJ Pretorius aan die Caledon gewerf is (VA R 19/38) en aan ander. Net so mag nie vergeet word nie Maritz en sy geselskap se deelname aan die eerste veldtog teen Silkaats en die Maritz- en Uysgroepe se deelname aan die tweede. Uiteindelik egter is dit die gelofte van 9 Desember 1838 wat die verskil maak en die 1838 Natalgebeure in die middelpunt van die Trekgebeure plaas. Dit sou egter Transvaal word waar die Voortrekkerideaal die volle blom sou gee en die vrug sou voortbring van 'n deur die grootmag Brittanje erkende selfstandigheid.

Literatuurverwysings

BIRD, J 1965. The annals of Natal 1495 to 1845, Volume I. Facsimile Reprint. Cape Town: C Struik.

CHASE, JC 1968. The Natal Papers. Facsimile Reprint. Cape Town: C Struik.

DICKE, BH 1941. The Northern Transvaal Voortrekkers. Argiefjaarboek vir SA Geskiedenis. Vierde Jaargang, Deel I. Kaapstad: Staatsdrukker.

DUVENAGE, GDJ 1981. Van die Tarka na die Transgariep. Pretoria: Academica.

DUVENAGE, GDJ 1986. Die Groot Trek: Die Eerste Drie Jaar, Deel I: 1836, Vegkop. Pretoria: Afrikanervolkswag.

DUVENAGE, GDJ 1987. Die Groot Trek: Die Eerste Drie Jaar, Deel II: 1837. Die Manifes. Pretoria: Afrikanervolkswag.

ENGELBRECHT, SP 1938. Die Gelofte. Die Huisgenoot. Desember 1938. 
GIFFARD, A (ed) 1981. The reminiscences of John Montgomery. Cape Town: AA Balkema.

MULLER, CFJ 1943. Veertig jaar uit die lewe van die Voortrekkerleier Karel Landman (1796-1875). Historiese Studies 4/1. Universiteit van Pretoria.

SPIES, FJ DU T 1959. Die herinneringe van Voortrekkers soos opgeteken deur GA Ode. Historia 4/4.

[VA] PRETORIUS, HS; KRUGER, DW \& BEYERS, C (red) 1937. VoortrekkerArgiefstukke 1829-1849. Pretoria: Staatsdrukker.

[VM] PRELLER, GUSTAV S (II); 1920 (III) s a. Voortrekkermense, II \& III. Kaapstad: Nasionale Pers.

[VM] PRELLER, GUSTAV S 1924. Voortrekker Wetgewing: Notule van die Natalse Volksraad. Pretoria: Van Schaik.

WICHMANN, FAF 1962. Die wordingsgeskiedenis van die Zuid-Afrikaansche Republiek 1838-1860. Argief Jaarboek vir Suid-Afrikaanse Geskiedenis. Vierde Jaargang, Deel II. Pretoria: Staatsdrukker. 